LA-7337-MS

Informal Report

$\frac{3}{3}$
312

78

$. th 321

UC-15

Issued: June 1978

\title{
The Structure of Safeguards Systems
}

\author{
James P. Shipley
}


THE STRUCTURE OF SAFEGUARDS SYSTEMS

by

James P. Shipley

\begin{abstract}
AESTRACT
An effective safeguards system for domestic nuclear fuel cycle facilities consists of several important subsystems that must coordinate their functions with plant management and process control. The safeguards system must not unnecessarily disrupt plant operations, compromise safety requirements, or infringe on employee working conditions. This report describes concepts, which have been developed with the cooperation of the nuclear industry and the safeguards community, for achieving these objectives.
\end{abstract}

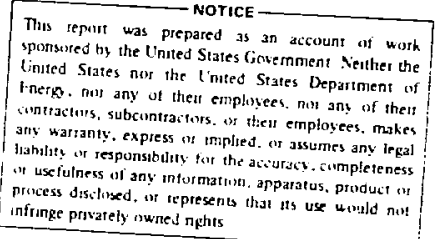

\title{
I. INTRODUCTION
}

The basic management, control, and coordination structure of safeguards systems for domestic nuclear fuel cycle facilities has been described in several earlier reports.1-7 This report does not address directly the problems of international safeguards or interactions with the International Atomic Energy Agency (IAEA). However, it should be recognized that the safeguards system structure discussed here would form the backbone of an effective operator's safeguards system in either national or multinational fuel cycle facilities. Such a safeguards system would significantly ease the application of IAEA safeguards.

A comprehensive safeguards strategy includes three functions: (1) exclusion of all unauthorized persons from the facility, with further selective exclusion of others from sensitive areas within the plant; (2) control of all activities involving strategic nuclear materials (SNM) so that each such activity is 
specifically authorized; and (3) confirmation that all materials are contained in their proper locations. The system for implementing that strategy must operate without unnecessary disruption of plant operations, compromise of safety requirements, or infringements on employee working conditions.

The following describes a system structure for accomplishing these goals. The concepts have been developed through numerous interactions with the nuclear industry and the safeguards community.

\section{GENERAL STRUCTURE OF SAFEGUARDS SYSTEMS}

The general block diagram of the fasility and the safeguards system is shown in Fig. 1, with those functions directly related to the process enclosed in heavily outlined boxes. The processcontrol function is distributed along the process and itemoperations lines in the form of local controllers, one for each portion of the process. The actions of the process controllers are supervised by the process-control coordination unit (PCCU). This hierarchical control is usually implemented through setpoint commands in which the operating point of each portion of the process is specified by the PCCU on the basis of operational authorizations, process-operation considerations, and safety. Many portions of the process may be self-regulating, requiring only that they be monitored for limit conditions.

The PCCU is also responsible for implementing safeguardsrelated recommendations that affect process operations. This implementation is necessa:y to ensure effective compliance from both the safeguards and process-control viewpoints. The materials measurement and accounting system (MMAS) and the PCCU also exchange process-related information to improve process operation and safeguards effectiveness.

The safeguards coordination unit (SCU), described in more detail in Ref. 4, supervises SNM safeguarding in the facility. As the focal point for safeguards decisions, the unit interacts with management and process-conirol coordination to ensure effective safeguards. Safeguards coordination must be as simple and reliable as possible, and its decision-making function must be balanced to avoid frequent false alarms that cause unnecessary process disruptions, while maintaining a high probability of effective response to any credible safeguards violation.

The SCU would normally rely on automated decision and control augmented by human supervision in abnormal. situations. Although it is the heart of the safeguards system, the SCU must be carefully designed to minimize single-point vulnerability and to reduce the necessary response time to rapidly developing threats. The physical protection system (PPS) controls personnel entry and exit for the facility and for restricted areas inside. The system includes automated equipment and enough guard forces to provide effective response in an emergenc 1 . It expands the conventional security functions, such as personnel control, to include control of item-handing operations. This arrangement provides more effective protection through remote, overriaing 

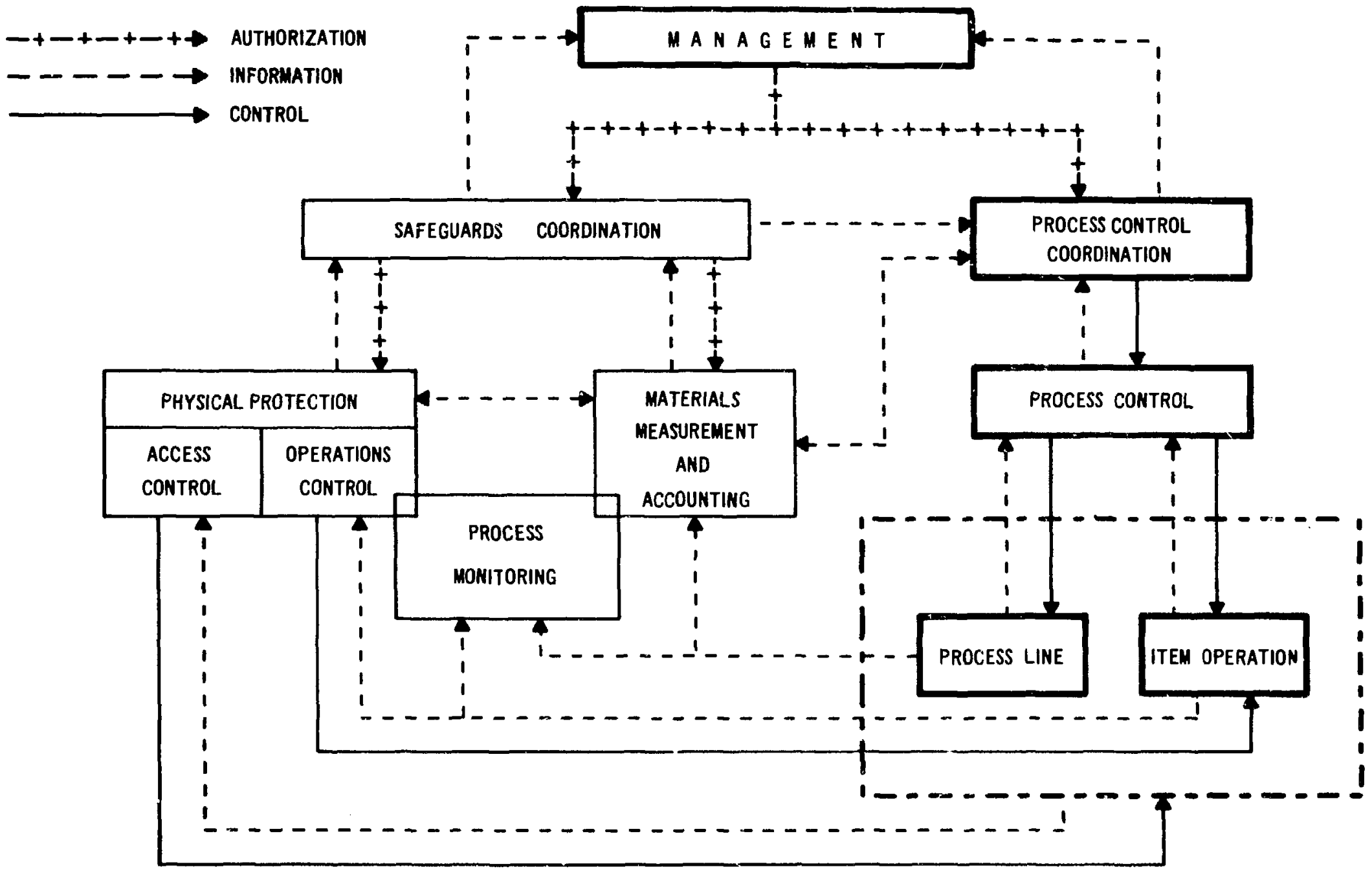

Fig. 1. Structure of the safeguards system. 
control of discrete material items in handling and storage. The concept is applied only to those portions of the facility, such as the loadout area, that are outside the closely coupled process line where material flow is not critical to smooth process operations.

The PPS provides appropriate information to the safeguards system and

- excludes all unauthorized persons and contraband from the facility,

- admits only essential persons to selected areas, and

- precludes unauthorized activities involving nuclear material and vital equipment.

Important objectives in the design of the PPS are to automate its functions whenever possible and to harden the system against subversion. These objectives are consistent with the stated goal of reducing dependence on personnel reliability.

In the current concept of domestic safeguards, the physicalprotection and materials-accounting functions complement and reinforce each other. In particular, the PPS protects not just nuclear material, but the integrity of tine MMAS as well. Conversely, the MMAS confirms the effectiveness of the PPS. This approach requires a high level of technological sophistication in the system design and operation, supplemented by thorough and Erequent plant and safeguards inspections by a knowledgeable, independent safeguards staff.

The design and evaluation of the PPS for these facilities is the responsibility of Sandia Laboratories. This area is discussed in detail in Refs. 2 , 3 , and 7 .

The MMAS is an implementation of the DYMAC concept 8,9 and is similar in principle to that already described for several types of facilities. It combines conventional chemical analysis, weighing, and volume measurements with the near-real-time measurement and surveillance capabiiities provided by NDA instrumentation to enhance rapid and accurate assessment of the location and amount of SNM in a facility.

The process-monitoring function combines elements of both the PPS and MMAS and provides supplementary information to each regarding compliance of actual process operating modes with approved procedures. The concept may be regarded as an extension of physical-protection monitoring and surveillance functions into the process line, and as an upgrading of the monitoring devices (or appropriate placement of them) to allow gross materials accounting.

The process-monitoring system collects timely information to detect a theft in progress from a limited set of on-line measurement equipment, plant-grade instrumentation, and cther simple, reliable process-monitoring devices. The system uses plant instrumentation wherever pcssible to assess approximate material balances on transfers between tanks and across columns. Similarly, an overall plutonium balance can be maintained. This balance is crude by accounting standards but has the advantage of near-real-time availability. 
The system also uses an array of sensors to provide information on the status of process valves: presence or absence of liquid in process, sampler, and deconiamination lines; status of valves supplying sample or transfer jets; and pressures in instrument lines. These sensors are all simple, rugged, and relatively inexpensive. This report will not discuss the physical protection and process monitoring systems beyond the brief functional descriptions given.

The safeguards computer system plays an essential role in implementing effective safeguards by collecting safeguardsrelated data and maintaining and controlling the safeguards information system. A major part of this role is the protection of SNM; an equally important part is the operational effect of the computer system on the processing of nuclear material. This occurs because information provided through the computer system forms the basis for all safeguards decisions, which may have varying degrees of effect on the process. Erroneous or unavailable information can degrade decision quality and cause unnecessary process disruptions. Thus, the reliability and integrity of the computer system directly affect economical operation of the process.

Several of the many possible computer and information system implementations are discussed in Refs. 2 and 4. In addition, the TRW Defense and space systems Group, under subcontract to Sandia Laboratories, is now investigating this area and refining alternatives. References 10 and 11 present some of their preliminary results and discuss system security and reljability. Reference 12 presents availability analyses for several alternative high-reliability computer systems.

\section{$+T \cdot$ SAFEGUARDS SUBSYSTEMS}

A. Plant Management

The plant management structure is straightforward and similar to traditional configurations. The major difference is the presence of the safeguards system, with the requirement that the plant and its management be responsive to safeguards considerations. A block diagram of the management structure and of the authorization, information, and contrc data paths is shown in Fig. 2 .

Management operations consist of tre fo'lowing steps.

- The general manager makes a decision on a fuel contract and issues authorization to proceed with processing.

- The general manager's fuel projects staff defines the scope of the work and issues a work order to the plant manager.

- The plant manager and his staff, using the process information system, plan and schedule the work load.

- The plant manager combines the work plan with any safeguards constraints and issues authorization to start work. A shop order describes the technical requirements and scheduling. The same information is transmitted to the safeguaras system. 


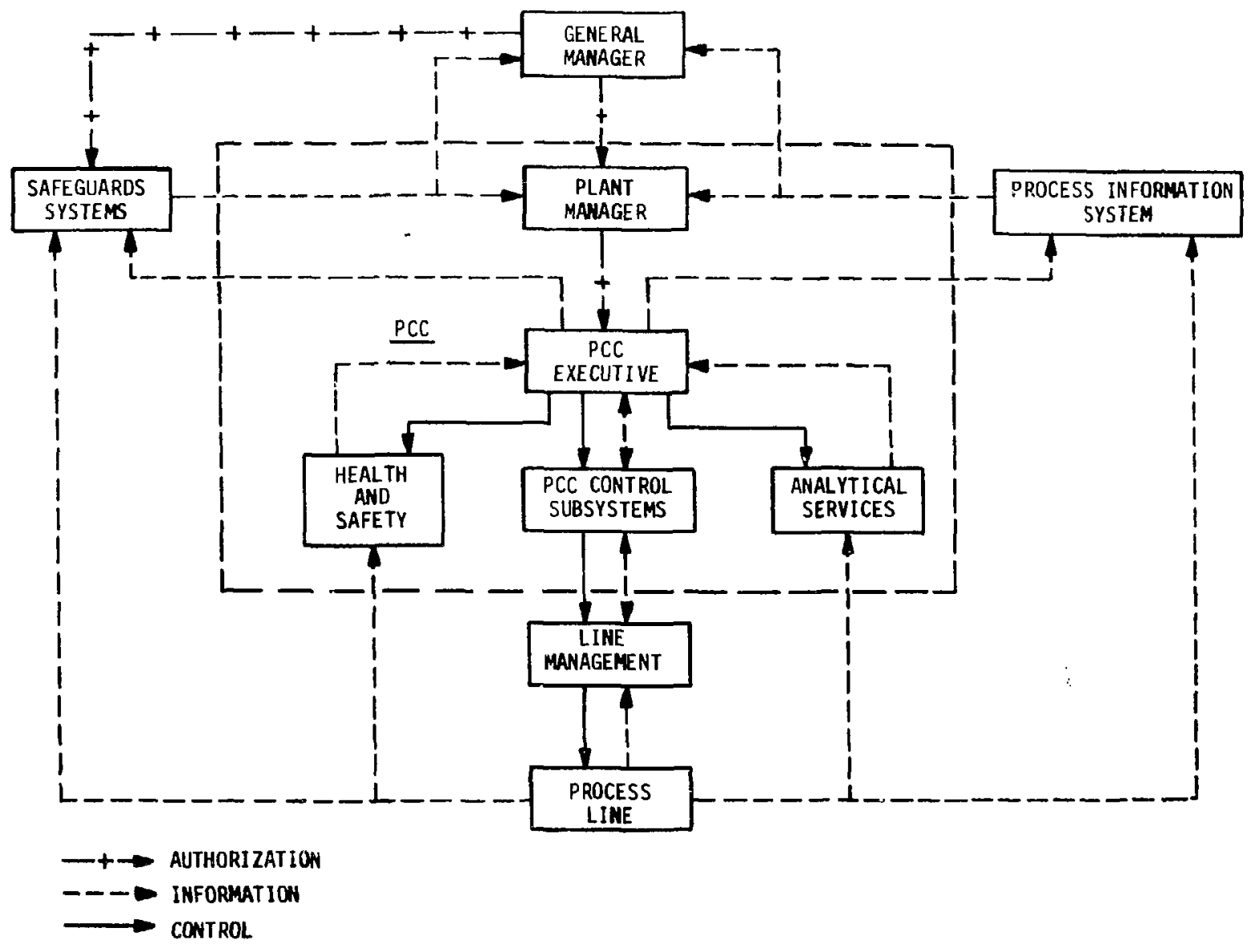

Fig. 2. Plant management structure. 
- The plant manager continually reviews the shop order status and safeguards system inputs and initiates any necessary action.

- Line management, with the help of PCC, organizes the work load and executes process operations on the basis of feedback from the process line, QC (ASF), and health and safety, and on data from the process information system.

- QC releases and maintains surveillance on product quality, analytical instrumentation calibration and inspections, and analytical data.

- Health and safety continually monitors all safety requirements for the plant, including criticality-related material transfers.

- The safeguards system continually assesses the safeguards status of the plant and makes action recommendations to the general manager and plant manager in case of possible safeguards breaches.

\section{B. Process Control}

The primary requirement of process control is uptimal operation of the process line. This requirement has three important aspects: (1) economical operation, (2) health and safety considerations, and (3) effective safeguarding of SNM.

The economia factor must obviously be emphasized in a privately operated commercial facility. Economy of operation is accomplished by designing the process control to maximize throughput while consuming minimum resources. This requires that the process be operated at the design rate with as few interruptions as possible.

The adequate safeguarding of SNM could have an adverse impact on the economical operation of the plant. Consider the case of a small amount of plutonium lost from the process at some intermediate point. Normal process control would probably ignore this event; indeed, it would probably be unaware of it. However, the safeguards system, through its MMAs, is expected to detect the loss and ask for an investigation, and some interruption of operations may be necessary while the source of the problem is determined. If the loss is the result of malicious, purposeful diversion of SNM, or is a false alarm, the process control function tends to regard the interruption as a nuisance. On the other hand, if the loss is benign (e.g., equipment malfunction or SNM leak), process control receives useful and otherwise unavailable information from the safeguards system. This is also true during normal operations because the MMAS monitors the material flows in greater detail and with more accuracy than the process control system. The material flow data are accessible by the process control function through the adaptive data link to the MMAS (Fig. 3).

These considerations result in a slightly different concept of process control than that normally followed. The process control function must be willing and able to interact with the 


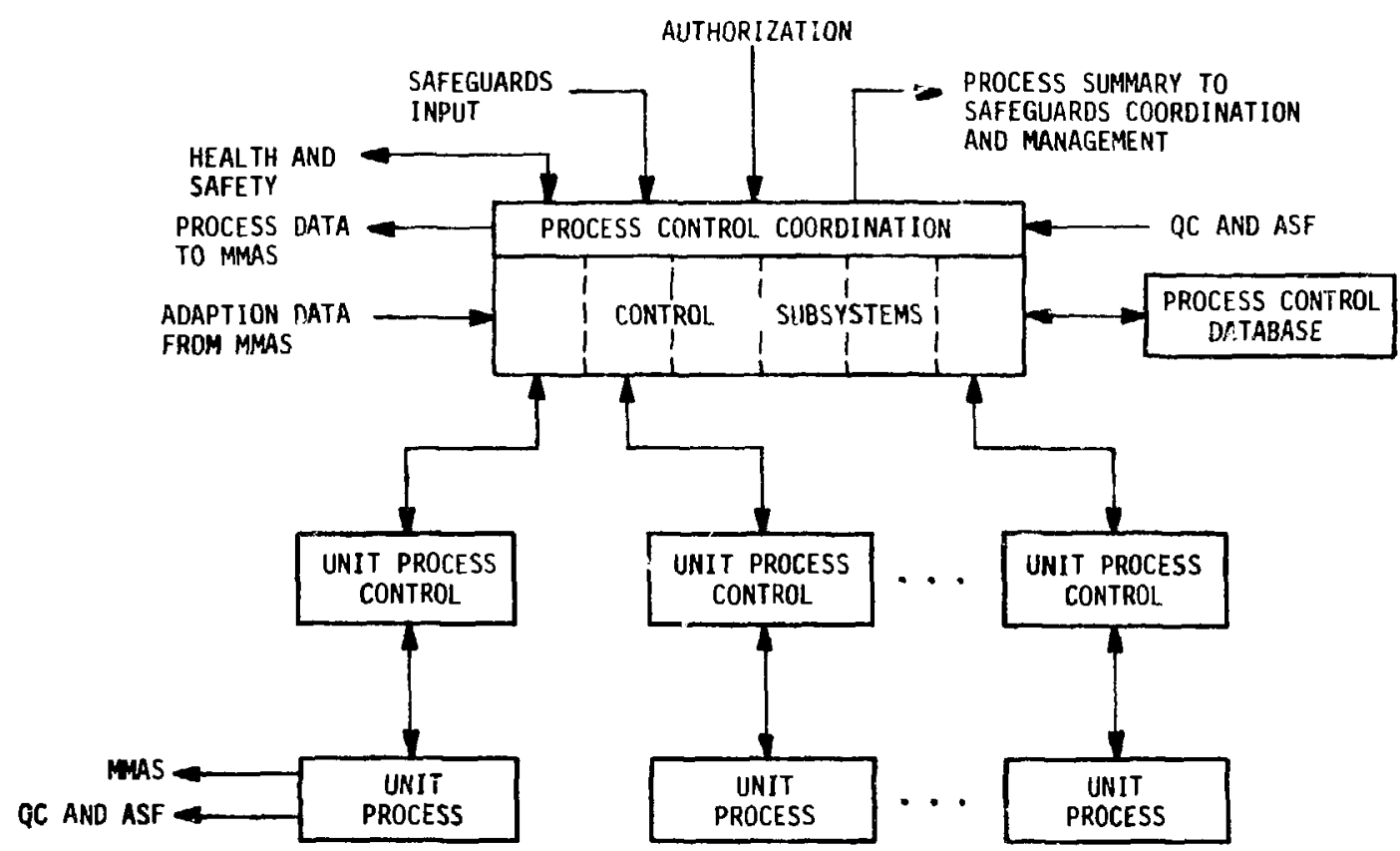

Fig. 3. Process control hierarchy. 
health and safety and safeguards functions so that all three operational requirements are satisfied.

The process line is divided into a number of unit processes, each having its own unit process controller (UPC) that reports to one of the control subsystems (Fig. 3). In addition to the control subsystems, the PCCU also contains other subsystems not directly concerned with process control.

The PCCU is responsible for the coherent operation of the entire process line -- it performs a supervisory function. It determines operating levels and operational sequences for each UPC so that they $a 11$ work together. This form of hierarchical control is called setpoint control and is the traditional method of controlling complex systems. It has been proven effective and is well understood in the process control field.

This hierarchy allows each UPC to be devoted to one relatively simple unit process, thereby simplifying the UPC design because interactions with other unit processes are handled by PCCU. The control may be manual, automatic with manual override, or a combination of these. The primary information transferred from PCCU to the UPC is the desired setpoint of the unit process. However, PCCU is also capable of retrieving UPC operating histories that have been compiled from past data. The instrumentation required for process control of some unit processes is also useful for materials accounting. The resulting measurement data are sent in parallel to LMAS.

C. Safeguards Coordination Uni'

As the central component of the safeguards system, the scu has three primary functions: (1) data collection ard processing, which is required for (2) safeguards condition assessment, which in turn is the basis for (3) the response determination decision. A structural diagram of the sCU is shown in Fig. 4.

To make good decisions, the SCU must have access to all pertinent safeguards data, management inputs, and process control information. Current safeguards data are available from the physical protection, process monitoring, and materials measurement and accounting systems, and the safeguards operating history is stored in the data base of the safeguards information system. All management authorizations are sent in parallel to the SCU and to their primary destinations, and the process control data summary can be acquired from the process information system through the PCCU executive.

Much of the information available to the SCU is not in a form suitable for decision making. The data processing block summarizes and formats the data for output at the display console. In addition, it generates the safeguards reports required for management and the regulatory authority.

The Safeguards officer uses the data processing information output at the display console to perform the condition assessment function. The result of the condition assessment is the plant's status with respect to safeguards requirements. Many of the minor condition assessments can be automated with manual override, but many require direct action from the Safeguards officer. 


\section{SAFEGIUARDS COORDIRATION SYSTEM (SCU)}

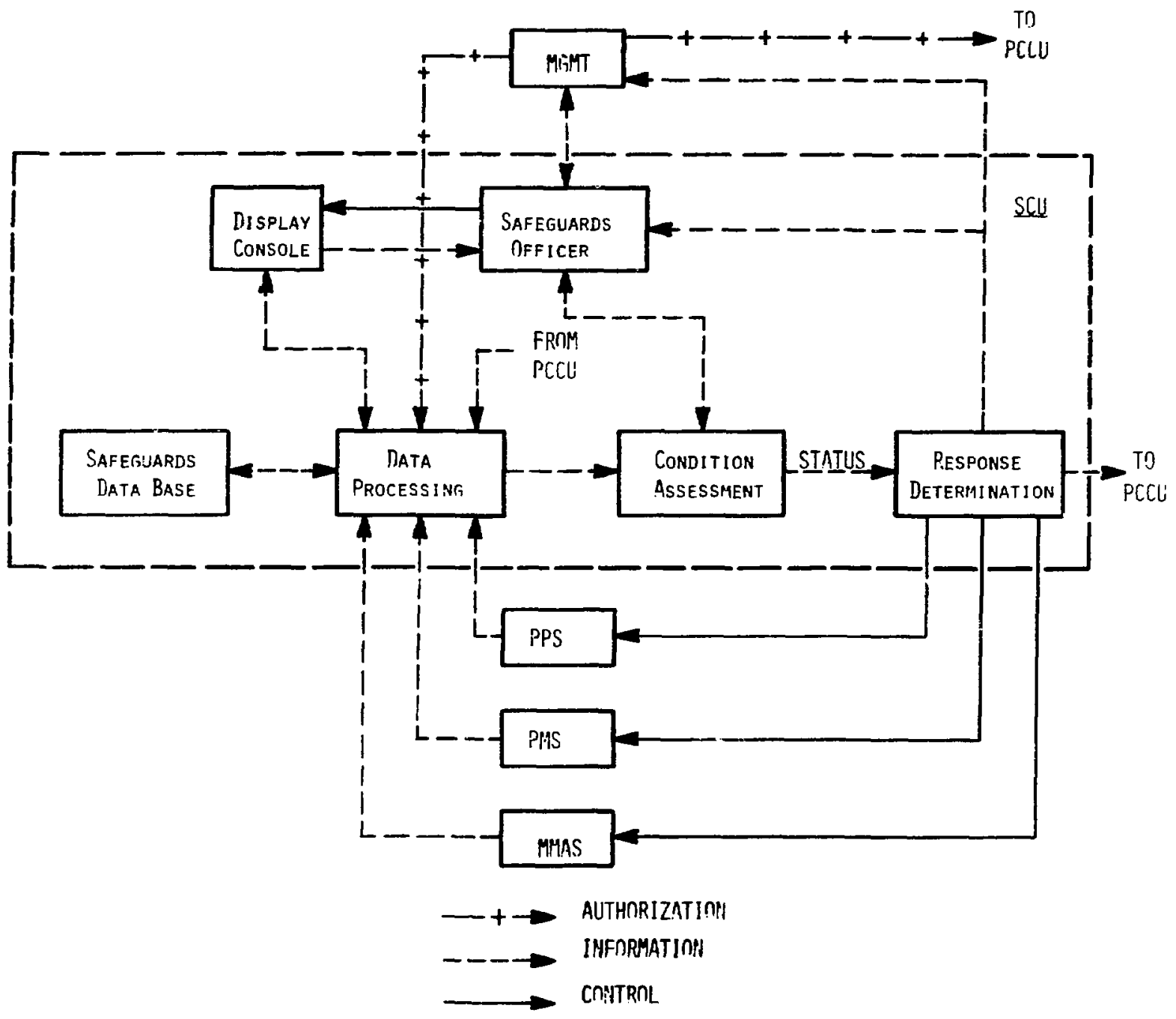

Fig. 4. Structure of the safeguards coordination system. 
Incoming SCU data are machine-monitored for possible indications of status changes (for example, by observing material imbalances or machine failures), and a response to each possible change is requested from the Safeguards officer. He then evaluates the plant safeguards status and determines appropriate responses for the PPS, PMS, and MMAS, taking into account process operations. These responses are transmitted to management and PCCU, along with recommendations for modified process authorizations.

As many status/response situations as possible are standardized in a manual of operating procedures. This manual ior appropriate portions thereof) is available to plant personnel on a need-to-know basis. Of course, standard procedures may not have been written up for many situations, and that is the main reason for the Safeguards officer. This scheme combines the efficiency of a machine in data handling with the adaptability of a human supervisor in making decisions.

In assessing the condition of the plant, the safeguards officer uses status reports from various parts of the plant. Taken together, these status reports constitute the plant status, which is stored in great detail in the safeguards and process information systems. However, the information normally displayed to the Safeguards officer is condensed for quick assessment, with nonstandard situations flagged to indicate areas that should be investigated. The Safeguards officer can ask for more detail, either in response to a flag or of his own volition.

The SCU recommendations can range from no recommendation to the extremes of process shutdown and plant evacuation. If the safeguards system is successful, there will most frequently be no recommendation at all. In any case, the course of action in abnormal situations is chosen by agreement among the safeguards Officer, plant management, and PCCU, although some responses may be dictateó by regulation.

D. Materials Measurement and Accounting system

The MMAS has three major tasks as regards SNM accounting:

- Data collection (including measurements),

- Data analysis (for diversion detection), and

- Data dissemination or reporting.

As currently performed by conventional safeguards inventory control, these tasks rely heavily on material-balance accounting following periodic shutdown, cleanout, and physical inventory. The classical material balance associated with this system is drawn around the entire plant or a major portion of the process, and is formed by adding all measured receipts to the initial measured inventory and subtracting all measured removals and the final measured inventory. During routine production, materials control is vested largely in administrative and process controls, augmented by secure storage for discrete items.

Although conventional material-balance accounting is essential to safeguards control of nuclear material, it has inherent limitations in sensitivity and timeliness. The first limitation results from measurement uncertainties that desensitize the system to losses of trigger quantities of SNM for large-throughput 
plants. The timeliness of traditional materials accounting is limited by the frequency of physical inventories. There are practical limits on how often a facility can shut down its process and still be productive.

Recently developed NDA technology, state-of-the-art conventional measurement methods, special in-plant sensors, plant instrumentation signals, and the most effective statistical dataanalysis techniques combined with supportive computer and database-management teconology make several more effective methods feasible. For example, conventional methods can be augmented by unit-process accounting, 4-6,8,9 where the facility is partitioned into discrete accounting envelopes called unit-process accounting areas (UPAAs). A unit process can be one or more chemical or physical processes and is chusen on the basis of process logic and whether a material balance can be drawn around it. By dividing a facility into unit processes and measuring all significant material transfers, quantities of material much smaller than the total plant inventory can be controlled. Furthermore, any discrepancies are localized to that portion of the process contained in the UPAA.

Material balances drawn around such unit processes during plant operation are called dynamic material balances to distinguish them from balances drawn after a cleanout and physical inventory. Ideally, the dynamic material balances would all be zero unless nuclear material had been diverted. In practice they never are, for two reasons. First, measured values are never exact because of the errors inherent in any measuring procedure. Second, constraints on cost or effects on materials processing operations may dictate that not all compor nts of a material balance be measured equally often; therefor, even if the measurements were exact, the material-balance values would not be zero until closed by additional measurements. In the interim, it is sometimes possible to use historical data as estimates of unmeasured material, and then update the estimates when additional measurements become available.

A consequence of the unit-process accounting, the concept of overlapping unit-process accounting areas, derives from the fact that two adjacent UPAAs can be combined to form a larger one, eliminating the intervening transfer measurement. This combination may be useful for cross-checking purposes and allows continued materials accounting (at reduced sensitivity and timeliness) in case of instrument malfunction.

These ideas must be used in a flexible fashion throughout the facility. Their application should be graded according to the safeguards strategic value and vulnerability of the material; hence, the concept of graded safeguards. For example, in the fuel reprocessing plant, plutonium nitrate at the loadout station is a much more attractive material to a potential divertor than is the highly radioactive dissolver solution at the headend of the process. Thus, more stringent safeguards at the loadout station than at the dissolver tank make good sense. 
E. Safeguards Computer Network

In conventional safeguards systems, filling out and transmitting large numbers of materials accounting forms requires much time and effort. These forms include records of receipts, shipments, internal transfers, and accounting measurement data. The possibilities for human error, eitner unintentional or malicious, are rife, and inefficiency in data management is unavoidable.

Such problems can be greatly alleviated by implementing the MMAS thrcugh computerized data acquisition and data-base management, with the conventional system retained as a backup in case of malfunction. Under this scheme, most instruments are interfaced directly to the computer system, and the use of computer terminals for data input is minirnized. Security problems are eased somewhat, and a self-verification capability is easily available by designing instrumentation for periodic on-line recalibration under computer control. Data from sources not connected to the computer system may still be entered through a minimal number of terminals.

The computer system acts as the central data manager for materials measurement and accounting and serves as a powerful tool in analyzing accounting data for possible SNM diversion. It generates all permanent records of materials quantities, locations, and movements, and, on demand, can provide reports required for effectiveness assessment, the current status of the safeguards system, and so on. In addition, the computer system interacts with the other safeguards elements to ensure most efficient use of all safeguards data. Furthermore, data may be exchanged as required with the PCCU to improve both safeguards and process control.

If all elements of the safeguards system are assisted by computerized operations, then their combined capabilities can provide significant improvements in security and reliability. Some possible configurations for the computer network are discussed in Refs. 4, 10, and 11 .

F. Data Analysis for Diversion Detection

Analysis of materials accounting data for possible SNM diversion is one of the major functions of the MMAS. Diversion may occur in two basic patterns: short-term diversion (the single theft of a relatively large amount of SNM), and long-term diversion (repeated thefts of SNM on a scale too small to be detected in a single material balance because of measurement uncertainties).

The use of unit-process accounting and dynamic material balances enhances the ability to detect such diversions, but it also means that the operator of the safeguards system will be inundated with materials accounting data. Furthermore, although these data contain much potentially useful information concerning both safeguards and process control, the siguificance of any isolated (set of) measurements is seldom readily apparent and may change from day to day, depending on plant operating conditions. Thus, the safeguards system operator is presented with 
an overwhelmingly complex body of information from which he must repeatedly determine the safeguards status of the plant. Ciearly, it is imperative that he be assisted by a coherent, logical Eramework of tools that address these problems.

Decision anaiysis (see Refs. 5, 13-16), which combines techniques from estimation theory, decision theory, and systems analysis, is such a framework, and is well suited for statistical treatment of the imperfect dynamic material-balance data that become available sequentially in time. Its primary goals are (1) detection of the event (s) that SNM has been diverted, (2) estimation of the amount (s) diverted, and (3) determination of the significance of the estimates.

The detection function is based on acceptance of the hypothesis that some (initially unknown) amount of SNM has been diverted, versus the hypothesis that no diversion has occurred. One liseful kind of decision test compares a likelihood ratio to a threshold, the likelihood ratio being defined roughly as the ratio of the probability that SNM has been diverted to the probability that it has not, with the threshold determined by the desired false-alarm and detection probabilities.

The estimation function can take several forms, including that of the Kalman filter applied to the material-balance equation. 5,14-21 Additional information, such as detailed process flow models, may be incorporated as desired. Effective estimation algorithms can greatly improve the detection function.

Pattern recognition techniques can be very useful for determining the significance of the estimates. One such tool is the alarm-sequence chart, which indicates (1) those material-balance sequences for which the possibility of diversion has been detected, (2) the false-alacm probability for that level of diversion, and (3) the length of the sequence. This chart has been most useful in separating material-balance sequences with both normal unmeasured sidestreams and diversion from those withou' diversion. 4,22

Decision analysis based on mathematically derived decision functicns is appealing because it can quantify intuitive feelings and condense large collections of data to a smaller set of more easily understood descriptors (statistics). It can also eliminate personal. biases and other errors caused by subjective evaluation of data while providing a degree of consistency for the decision process.

In an actual operating situation, the safeguards system operator will need a readily available battery of such techniques. One test or another often will yield inconclusive results, so that additional tests may provide additional evidence to support the decision function. However, informed reason must govern interpretation of the test results. The fact that two differert tests applied to the same data give similar (or at least consistent) results may or may noic be significant depending on the degree of independence of the tests; completely independent tests are clearly the most desirable. 
The safeguards system operator must be able to apply the test.j quickly and easily in whatever Eashion seems most $a_{2}$ opri-'s at the moment, within the limit of good statisticalanalysis practice, with reasonable assurance that he can understand the meaning of the results. It is unrealistic to expect all users to be equally proficient in test applications and interpretations. Careful design of the human-engineering aspects of the tests minimizes these difficulties and enhances the utility of the diversion-detection function.

\section{CONCLUSION}

The safeguards system structure discussed above incorporates the latest safeguards concepts as determined by extensive interactions with the nuclear industry and workers in the safeguards field. These concepts provide not only guidance in developing new systems, but also a means of assessing the effectiveness of existing systems. The ideas are general enough to apply to any of the proposed alternative fuel cycles with only changes in detail.

The safeguards system can be implemented in many different ways using various levels of hardware sophistication. These range from completely automated, computerized systems to those that rely extensively on the human element. The optimum configuration is likely a mix of the two extremes, one that synergistically provides the best features of both.

\section{REFERENCES}

1. J. M. de Montmollin and R. B. Walton, "The Design of Integrated Safeguards Systems for Nuclear Facilities," Nucl. Mater. Manage. V(III), 317-332 (1976).

2. L. D. Chapman, J. M. de Montmollin, J. E. Deveney, W. C. Fienning, J. W. Hickman, L. D. Watkins, and A. E. Winblad, "Development of an En neered Safeguards System Concept for a Mixed-Oxide Fuel Fal ication Facility," Sandia Laboratories report SAND76-0180 (August 1976).

3. W. C. Fienning, A. E. Winblad, and J. P. Shipley, "A Preliminary Concept Definition of a Combined Safeguards System for a Mixed-oxide Fuel Fabrication Facility," sandia Laboratories report, to be published.

4. J. P. Shipley, D. D. Cobb, R. J. Dietz, M. L. Evans, E. P. Schelonka, D. B. Smith, and R. B. Walton, "Coordinated Safeguaras for Materials Management in a Mixed-oxide Fuel Facility," Los Alamos Scientific Laboratory report LA-6536 (February 1977). 
5. E. A. Hakkila, D. D. Cobb, H. A. Dayem, R. J. Dietz, E. A. Kern, E. P. Schelonka, J. P. Shipley, D. B. Smith, R. H. Augustson, and J. W. Barnes, "Coordinated Safeguards for Materials Management in a Fuel Reprocessing Plant," Los Alamos Scientific Laboratory report LA-6881 (September 1977).

6. H. A. Dayem, D. D. Cobb, R. J. Dietz, E. A. Hakkila, E. A. Kern, J. P. Shipley, D. B. Smith, and D. F. Bowersox, "Coordinated Safeguards for Materials Management in a Nitrateto-oxide Conversion Facility," Los Alamos Scientific Laboratory report LA-7011, (April 1978).

7. W. D. Chadwick, W. C. Fienning, B. G. Self, and G. E. Rochau, "A Concept Definition of an Engineered Safeguards System for a spent Fuel Reprocessing Facility," Sandia Laboratories report, to be published.

8. R. H. Augustson, "Development of In-Plant Real Time Materials Control: The DYMAC Program," Nucl. Mater. Manage. V(III), 302-316 (1976).

9. G. R. Keepin and W. J. Maraman, "Nondestructive Assay Technology and In-Plant Dynamic Materials Control--DYMAC," in Safeguarding Nuclear Materials, Proc. Symp., Vienna, 1975 (International Atomic Energy Agency, Vienna, 1976) paper IAEA-SM-201/32, pp. 305-320.

10. J. H. Fuchs, D. M. Kisner, R. K. McClean, H. R. Milder, K. Mizuba, and G. E. Short, "Unified Safeguards Information Syster Concept," TRW Defense and Space Systems Group report 32076-6001-RU-00 (May 20, 1977).

11. D. M. Kisner, H. R. Milder, and K. Mizuba, "Preliminary Hardware Configuration Recommendations for Safeguards Information System," TRW Defense and space systems Group report 31134-6001-RU-00 (May 24, 1977).

12. E. P. Schelonka. "Availability Analysis for High-Reliability Computer Systems in Nuclear Facilities," Proc. 18th Ann. Mtg. Instit. Nucl. Mater. Mgmt., Washington, DC, June 29-July $1,1977$.

13. R. A. Howard, "Decision Analysis: Perspectives on Inference, Decision, and Experimentation," Proc. IEEE, Spec. Iss. Detection Theory and Appl. 58, No. 5, 632-643 (May 1970).

14. J. P. Shipley, "Decision Analysis in Safeguarding Special Nuclear Material," invited paper, Trans. Am. Nucl. Soc. 27 , $178(1977)$. 
15. James P. Shipley, "Decision Analysis for Nuclear Safeguards," paper presented to the 1978 Spring Mtg. Am. Chem. suc. on Nondestructive and Analytical Chemical Techniques for Nuclear Safeguards, Anaheim, California, March 12-17, 1978.

16. James P. Shipley, "Decision Analysis for Dynamic Accounting of Nuclear Material," paper presented at the Am. Nuc. Soc. Topical Mtg., Williamsburg, Virginia, May 15-17, 1978.

17. R. E. Kalman, "A New Approach to Linear Filtering and Prediction Problems," Trans. ASME J. Basic Eng. 82D, 34-45 (March 1960).

18. R. E. Kalman and R. S. Bucy, "New Results in Linear Filtering and Prediction Theory," Trans. ASME J. Basic Eng. 83D, 95-108 (March 1961).

19. D. H. Pike, G. W. Morrison, and C. W. Holland, "Linear Filtering Applied to Safeguards of Nuclear Material," Trans. Am. Nucl. Soc. 22, 143-144 (1975).

20. D. H. Pike, G. W. Morrison, and C. W. Holland, "A Comparison of Several Kalman Filter Models for Establishing MUF," Trans. Am. Nucl. Soc. 23. 267-268 (1976).

21. D. H. Pike and G. W. Morrison, "A New Approach to Safeguards Accounting," Oak Ridge National Laboratory report ORNL/CSD/ TM-25 (March 1977).

22. D. D. Cobb, D. B. Smith, and J. P. Shipley, "Cumulative Sum Charts in Safeguarding Special Nuclear Materials," unpublished report (December 1976). 